\title{
Potential sources of bias in the use of individual's recall of the frequency of exposure to air pollution for use in exposure assessment in epidemiological studies: a cross-sectional survey
} Paul R Hunter*1, Karen Bickerstaff² and Maria A Davies ${ }^{3}$

\author{
Address: ${ }^{1}$ School of Medicine, Health Policy and Practice, University of East Anglia, Norwich NR4 7TJ, UK, ${ }^{2}$ School of Environmental Science, \\ University of East Anglia, Norwich NR4 7TJ, UK and ${ }^{3}$ Health Protection Agency, Countess of Chester Health Park, Chester CH2 1UL, UK \\ Email: Paul R Hunter* - paul.hunter@uea.ac.uk; Karen Bickerstaff - K.Bickerstaff@uea.ac.uk; Maria A Davies - maria.davies@hpa.org.uk \\ * Corresponding author
}

Published: 3I March 2004

Environmental Health: A Global Access Science Source 2004, 3:3

This article is available from: http://www.ehjournal.net/content/3/I/3

(C) 2004 Hunter et al; licensee BioMed Central Ltd. This is an Open Access article: verbatim copying and redistribution of this article are permitted in all media for any purpose, provided this notice is preserved along with the article's original URL.
Received: 17 February 2004

Accepted: 3I March 2004

\begin{abstract}
Background: In a previous study it has been shown that mean population perception of air pollution correlates well with physical measures of actual air pollution and could be used as a measure of exposure to air pollution, at least for those forms of pollution perceptible to humans. However, for such a measure to be valid researchers would need to be confident that it was not strongly biased by possible confounding variables. This study reports the association between perception of above average levels of air pollution compared with others in the neighbourhood and a number of factors that may influence reporting.
\end{abstract}

Methods: This was a postal cross-sectional study of 3402 households in England in a mixed rural and urban area adjacent to a large industrial complex. Respondents were asked about their social and demographic characteristics, the presence of respiratory symptoms and frequency of exposure to a range of pollution types.

Results and discussion: There were strong associations $(p<0.01)$ with the presence of a person in the home with respiratory symptoms, the belief that industrial pollution was harming their health, social class, living in rented accommodation and reporting noise from neighbours and other people's smoke. Smoking behaviour did not affect reporting.

Conclusions: We did not find any evidence of bias that would substantially invalidate mean population reporting of air pollution severity as a measure of exposure in epidemiological studies, though care may be needed in interpreting results where those factors found to be significant in this study vary substantially between areas.

\section{Background}

In recent years, there have been many publications addressing the relationship between various types of air pollution and adverse health outcomes in human populations [1-6]. One of the problems faced by many of the studies covered by the reviews referred to in the previous sentence was accurately determining the degree of envi- ronmental exposure [7]. Getting accurate measures of exposure to airborne pollutants is especially problematic in large populations over prolonged time periods $[7,8]$. Individual reporting of the severity of exposure has been used in a very few studies [9], though analysis of individual perception of pollution is open to recall bias $[8,10]$. A recent paper has provided convincing evidence that 
population mean perception is a good indicator of air pollution [8].

Recent work has shown that population means of personal perception of exposure to various pollutants is highly correlated with actual exposure as measured by chemical monitoring and may even give a better estimate of exposure levels when there are relatively few sampling points $[8,11]$. Therefore, using population means of reported exposure to air pollution would be a valid measure of long-term pollution severity [8].

However, the use of perception about the severity of air pollution, on an individual or population level, has not gained general acceptance as a suitable measure of environmental exposure. Indeed a recent monograph on human exposure assessment did not even discuss people's perception as a marker for pollution severity [7].

In one epidemiological study of air pollution and ill health [10] it was noted that mean levels of self-reported air pollution corresponded closely with what would have been expected to be the case from prior knowledge of sources of pollution. However, individual reporting of exposure varied markedly even over very small areas. If individual reports of exposure are to be used in epidemiological studies, it is important to understand which factors affect such reporting, other than actual air pollution levels. Bias acting at the level of the individual is likely to be caused by many factors, though provided those factors are randomly distributed between populations, this will not lead to a systematic bias in the estimate of air pollution. If bias is shown to be caused by factors that show substantial variation between geographical locations, then this would undermine the use of annoyance scores as a measure of air pollution. This paper reports an analysis of our data to determine some of those factors.

\section{Methods}

The study was a large cross sectional survey of residents in the borough of Ellesmere Port and Nest in the North West Region of England. This borough, of 18 wards, covers both urban and rural areas and to the East of the borough is a large petrochemical industrial complex. The actual study is discussed in more detail elsewhere [9]. Of 6559 questionnaires sent out to residents across the borough (representing $10 \%$ of homes in the borough), 3402 $(51.9 \%)$ valid ones were returned. The questionnaires were sent to the 'head of the household' to be completed for all family members. Households were chosen randomly from each electoral Ward. Non-responders were sent a reminder letter 3 weeks later and if a response was not obtained this was followed up by a personal visit some 2 weeks later.
The questionnaire asked general questions about the household, about certain aspects of the health of family members and about their experience of certain types of pollution. In particular, respondents were asked to indicate their beliefs about the impact of pollution on their or their family's health. Respiratory illness was recorded if respondents answered yes to the question: "Does anyone in the household suffer from asthma, recurring wheezy breathing, recurring cough or shortness of breath at rest?"

The key dependant variable in this analysis was how frequently the respondent noted industrial odour air pollution (none, at least yearly, monthly, weekly and daily). Odour was only one of several markers of industrial pollution used in the study; other markers were industrial smoke, industrial fallout and industrial noise. Odour was chosen for this analysis because all markers were highly correlated and odour pollution was the marker most frequently reported and was also most strongly correlated with the presence of respiratory illness [10]. Odour pollution is also a significant issue in the area where the study was conducted. Furthermore, in a previous study of residents' concerns about the health effects of a petroleum plant, odour perception and annoyance was found to be the principal mechanism mediating ill-health reporting [12]. The median reporting frequency was calculated for each electoral ward area. Respondents were then categorised as high reporters if they reported odour pollution more frequently and low reporters if they reported odour pollution less frequently than the median for their area. It was assumed that odour pollution was relatively homogenous across each electoral area. Given that the main source of odour in the area came from a single industrial complex to the east of the town, this assumption is fairly safe.

Independent variables included in the initial analyses are listed in table 1 . Two other pollution variables that were unlikely to be directly related to odour pollution were also included in the analyses (reporting noise pollution from neighbours and reporting exposure to other peoples tobacco smoke). These were included in order to try and assess the individual's likelihood to report pollution experiences. Most variables are self explanatory. Social class is based on the UK Registrar General's classification [13]. Basically, people in social class 1 are professionals, 2 are semi-professionals, 3NM are non-manual skilled workers, $3 \mathrm{M}$ are skilled manual workers, 4 are semi-skilled and 5 are unskilled. Not all people can be easily classified, such as many retired people, unemployed or students. People were asked whether they believed that air pollution was harmful to their health. Further details are given in our earlier paper [10]. 
Table I: Single-variable analyses of increased reporting of industrial odour pollution.

\begin{tabular}{|c|c|c|c|c|c|c|c|c|}
\hline \multirow[t]{2}{*}{ Variable } & & \multicolumn{2}{|c|}{$\begin{array}{l}\text { Reduced reporting of industrial } \\
\text { pollution }\end{array}$} & \multicolumn{2}{|c|}{$\begin{array}{l}\text { Median reporting of industrial } \\
\text { pollution }\end{array}$} & \multicolumn{2}{|c|}{$\begin{array}{l}\text { Increased reporting of industrial } \\
\text { pollution }\end{array}$} & \multirow[t]{2}{*}{$\mathrm{P}$ value $\mathrm{a}^{\mathrm{a}}$} \\
\hline & & $n$ & $\%$ & $n$ & $\%$ & $n$ & $\%$ & \\
\hline \multirow[t]{2}{*}{ Presence of child in the home } & No & 688 & 28 & 1050 & 42 & 754 & 30 & $<0.0001$ \\
\hline & Yes & 210 & 23 & 343 & 38 & 357 & 39 & \\
\hline \multirow{2}{*}{$\begin{array}{l}\text { Presence of person in home with } \\
\text { respiratory symptoms }\end{array}$} & No & 677 & 29 & 1003 & 44 & 622 & 27 & $<0.0001$ \\
\hline & Yes & 221 & 20 & 390 & 35 & 489 & 44 & \\
\hline \multirow{3}{*}{$\begin{array}{l}\text { Believes industrial pollution is } \\
\text { harming their health }\end{array}$} & No & 184 & 29 & 367 & 58 & 84 & 13 & $<0.0001$ \\
\hline & Don't know & 485 & 33 & 636 & 44 & 337 & 23 & \\
\hline & Yes & 219 & 17 & 390 & 30 & 690 & 53 & \\
\hline \multirow[t]{7}{*}{ Occupational class } & 1 & 36 & 12 & 172 & 59 & 82 & 28 & $<0.0001$ \\
\hline & 2 & 108 & 17 & 314 & 48 & 226 & 35 & \\
\hline & $3 N M$ & 121 & 27 & 159 & 36 & 162 & 37 & \\
\hline & $3 M$ & 178 & 25 & 268 & 37 & 272 & 38 & \\
\hline & 4 & 167 & 35 & 150 & 32 & 154 & 33 & \\
\hline & 5 & 33 & 31 & 37 & 35 & 35 & 33 & \\
\hline & Undetermined & 255 & 35 & 293 & 40 & 180 & 25 & \\
\hline \multirow[t]{2}{*}{ Ownership of home } & Own home & 593 & 23 & 1104 & 43 & 853 & 33 & $<0.0001$ \\
\hline & Rented & 310 & 37 & 283 & 33 & 252 & 30 & \\
\hline \multirow[t]{2}{*}{ Uses gas for heating or cooking } & No & 304 & 24 & 613 & 48 & 367 & 29 & 0.4267 \\
\hline & Yes & 592 & 28 & 777 & 37 & 741 & 35 & \\
\hline \multirow[t]{3}{*}{ Has double glazing } & No windows & 377 & 31 & 449 & 37 & 391 & 32 & 0.008 \\
\hline & Some windows & 122 & 21 & 290 & 49 & 178 & 30 & \\
\hline & All windows & 395 & 25 & 653 & 41 & 539 & 34 & \\
\hline \multirow[t]{2}{*}{ Own pets } & No & 542 & 29 & 751 & 40 & 583 & 31 & 0.0006 \\
\hline & Yes & 351 & 23 & 637 & 42 & 522 & 35 & \\
\hline \multirow{2}{*}{ Current smoker in house } & No & 575 & 25 & 992 & 43 & 760 & 33 & 0.0585 \\
\hline & Yes & 323 & 30 & 401 & 37 & 351 & 33 & \\
\hline \multirow[t]{2}{*}{ Ever smoker in house } & No & 331 & 24 & 608 & 44 & 437 & 32 & 0.3654 \\
\hline & Yes & 567 & 28 & 785 & 39 & 674 & 33 & \\
\hline \multirow[t]{2}{*}{ Reports noise from neighbours } & No & 757 & 28 & 1184 & 43 & 783 & 29 & $<0.0001$ \\
\hline & Yes & $14 \mid$ & 21 & 209 & 31 & 328 & 48 & \\
\hline \multirow[t]{2}{*}{ Reports other people's smoke } & No & 833 & 29 & 1219 & 42 & 826 & 29 & $<0.0001$ \\
\hline & Yes & 65 & 12 & 174 & 33 & 285 & 54 & \\
\hline
\end{tabular}

a Where possible, $\mathrm{p}$ values are derived from Chi squared for trend.

All analyses were done using SPSS (Statistical Package for the Social Sciences). Univariable analyses were based on Chi-squared tests for trend. The multivariable analyses were done using multinomial logistic regression analysis. All variables with $\mathrm{p}<0.1$ were initially put into the logistic regression model and then least significant variable removed until all variables left in model had $\mathrm{p}<0.1$.

\section{Results}

The single variable analyses are listed in table 1 . Several of the variables were strongly associated with high and/or low reporting. Presence of a child in the home, presence of a person with respiratory disease, the belief that pollution is harmful, occupational class, home ownership and reporting noise and other peoples smoking as problems were all very strongly associated $(<0.0001)$ with reporting behaviour. Having double glazing and owning pets were also significant at the 0.05 probability level. Using gas for cooking or heating and people in the home currently smoking or with a history of smoking did not affect reporting behaviour.

The results of the multi-variable analyses are shown in table 2 . The presence of a person with respiratory disease in the home, the belief that pollution is harmful, occupational class, home ownership and reporting noise and other peoples smoking as problems were all very strongly and independently associated $(<0.001)$ with reporting behaviour. Home ownership was also associated with reporting behaviour. In particular, it is notable that respondents from homes with a person reporting respiratory symptoms were more likely to report odour pollution than the median and people with no-one with respiratory symptoms were less likely to report. Those people who believed air pollution was harmful to health were more likely to be high reporters, though belief was not associated with low reporting. For occupational class, people in lower social classes were distinct in that we see associa- 
Table 2: Final multivariable model for reporting of industrial odour pollution above and below the median, estimated from 3386 observations.

\begin{tabular}{|c|c|c|c|c|c|c|}
\hline \multirow[t]{2}{*}{ Variable } & & \multicolumn{2}{|c|}{$\begin{array}{l}\text { Reduced reporting of industrial } \\
\text { pollution }\end{array}$} & \multicolumn{2}{|c|}{$\begin{array}{l}\text { Increased reporting of industrial } \\
\text { pollution }\end{array}$} & \multirow[t]{2}{*}{$P$ value } \\
\hline & & Odds Ratios & $(95 \% \mathrm{Cls})$ & Odds Ratios & $(95 \% \mathrm{Cls})$ & \\
\hline \multirow[t]{2}{*}{ Presence of person in home with respiratory symptoms } & No & I & & 1 & & $<0.001$ \\
\hline & Yes & 0.749 & $0.612-0.916$ & 1.532 & $1.278-1.835$ & \\
\hline \multirow[t]{3}{*}{ Believes industrial pollution is harming their health } & No & 1 & & 1 & & $<0.001$ \\
\hline & Don't know & 1.413 & $1.131-1.765$ & 2.107 & $|.597-2.78|$ & \\
\hline & Yes & 1.061 & $0.822-1.370$ & 6.086 & $4.622-8.013$ & \\
\hline \multirow[t]{7}{*}{ Occupational class } & 1 & I & & I & & $<0.001$ \\
\hline & 2 & 1.638 & $1.072-2.502$ & 1.424 & $1.015-1.999$ & \\
\hline & $3 N M$ & 3.248 & $2.102-5.019$ & 1.828 & $1.26 \mid-2.650$ & \\
\hline & $3 M$ & 2.776 & $1.837-4.196$ & 1.625 & $1.157-2.283$ & \\
\hline & 4 & 4.367 & $2.836-6.725$ & 1.501 & $1.028-2.191$ & \\
\hline & 5 & 3.075 & $1.675-5.646$ & 1.516 & $0.847-2.715$ & \\
\hline & Undetermined & 3.324 & $2.214-4.990$ & 1.247 & $0.873-1.780$ & \\
\hline \multirow[t]{2}{*}{ Ownership of home } & Own home & 1 & & & & 0.002 \\
\hline & Rented & 1.484 & $1.182-1.863$ & 1.060 & $0.833-1.348$ & \\
\hline \multirow[t]{2}{*}{ Current smoker in house } & No & 1 & & 1 & & 0.071 \\
\hline & Yes & 0.807 & $0.668-0.974$ & 0.967 & $0.801-1.166$ & \\
\hline \multirow[t]{2}{*}{ Reports noise from neighbours } & No & 1 & & 1 & & $<0.001$ \\
\hline & Yes & 1.123 & $0.876-1.438$ & 1.621 & $1.304-2.017$ & \\
\hline \multirow[t]{2}{*}{ Reports other people's smoke } & No & 1 & & I & & $<0.001$ \\
\hline & Yes & 0.598 & $0.436-0.821$ & 1.779 & $1.407-2.250$ & \\
\hline \multirow[t]{3}{*}{ Has double glazing } & No windows & 1 & & & & 0.070 \\
\hline & Some windows & 0.746 & $0.566-0.982$ & 0.776 & $0.595-1.013$ & \\
\hline & All windows & 0.993 & $0.802-1.230$ & 1.035 & $0.836-1.281$ & \\
\hline
\end{tabular}

tions with both low and high reporting of respiratory problems (in other words we see both poles of behavioural response). People in rented accommodation were more likely to be low reporters. Finally general reporting of nuisance pollution (noisy neighbours and other people's smoke) was more frequent in high odour reporters. Low odour reporting was also associated with low reporting of other peoples smoke but not with reporting noisy neighbours.

\section{Discussion}

Should mean population perception gain acceptance as a measure of exposure to environmental pollution, it would offer a number of advantages. Firstly it would provide a fairly cost effective estimate of geographical variation in long-term pollution estimates. Secondly, if as has been argued, some of the adverse health effects of environmental pollution are mediated through psychological mechanisms related to perception $[9,14]$ then measures of perception may provide more useful predictors of adverse health effects.

Odour is a particularly complex sensation, requiring the interaction between odorous chemicals, olfactory neurones and substantial central processing $[15,16]$. The exact mechanisms whereby people will become aware of an odour are likely to vary depending on the particular mix of odorous chemicals. However, a purely olfactory mech- anism is most likely given the predominant petrochemical sources. This view is supported by the observation that odour was reported more frequently than other visual indicators of industrial pollution. The full mechanism for this process is beyond the scope of this article, other than saying that odour has been found to be an important marker of perceptions of air pollution and a significant factor for reporting adverse health $[10,12,16]$.

The observation of the association between having a person with respiratory disease in the house and increased reporting of air pollution is not surprising. Many studies have reported that individuals with disease are more likely to report increased exposure to presumed risk factors than is the case found by objective measurement. This is recall bias [17]. In the Swiss study, the authors found people with respiratory disease report higher pollution than the mean of people in their area [8]. Many studies of the association between disease and environmental exposure have suggested recall bias as a cause of apparently significant associations [18-22]. In the area of air pollution and respiratory disease, there are a number of mechanisms whereby this may happen. Firstly air pollution may exacerbate symptoms of respiratory illness so affected individuals are more aware of poor air quality because they are more symptomatic where air pollution is worse. Secondly should people with respiratory disease believe that their illness was caused by air pollution, they may over-report 
exposure. This is linked to belief about the harmful effects of air pollution discussed below. Although there is a risk that differences in the prevalence of respiratory disease could bias the population perception estimates of exposure severity, this is unlikely to be a major problem unless disease prevalence is extremely high.

The association with the belief that pollution is harmful for one's health or one's family's health is also not surprising and has been previously shown [23]. However, the association between increased reporting and belief was independent of the association with the presence of respiratory disease. This may be because of existing ill health, other than respiratory disease, or because respondents are worried that air pollution may be causing them harm that has yet manifested as physical illness. The mechanism of recall bias in this instance would be the same as for recall bias and the association with the presence of respiratory disease. One important issue in this regard is the social amplification of risk $[24,25]$. In this context, media reporting that emphasises risk to health of air pollution in a locality, as is the case in some parts of the study area in this investigation, may increase belief about the risks of air pollution and, the likelihood of recall bias for exposure. Such social amplification of risk sources of recall bias of exposure are likely to be more important in estimating exposure as more people may be affected by media reporting than by actual illness. Consequently the use of population mean perception of exposure as estimates of true exposure may be problematic if there has been significant local media interest in this subject irrespective of any objective measure of pollution.

The relationship between actual levels of air pollution, ill health and individuals' beliefs about the relationship between air pollution and ill health and the severity of air pollution locally is more complex than suggested so far. These variables are all highly correlated and have significant influences on each other and are in themselves influenced by several wider factors [23,26-31]. For instance, social science research has emphasised the role of trust relations, the (perceived) ability of individuals to take meaningful action to attenuate the effects of air pollution (e.g economically able to move, success in political lobbying etc) and satisfaction with the local neighbourhood in how people make judgements about the severity of urban and industrial air pollution [32-35]. To take the issue of neighbourhood satisfaction or commitment to place, research has consistently highlighted how those least happy with or committed to the local area are more likely to associate other social and environmental problems with their own neighbourhood [30,36]. This may be the explanation why we have found an association between reporting behaviour and both social class and home ownership.
The relationship between social class and reporting behaviour in this study is complex. Relative to people in socio-economic group 1, people in lower social classes are more likely to be both low reporters, and paradoxically also high reporters. Why this should be the case is unclear. However, the main effect is due to low reporting in people from lower social groups. Other workers have shown the relationship between socio-economic class and concerns about air pollution and shown that this relationship is complex [37]. Nevertheless, the finding that people from lower socio-economic groups are more likely to both under and over-report would minimise any bias on estimation of air pollution from social class effects. Although the range of reporting is greater in lower social classes the median is the same for all social classes.

The association with reporting of industrial odour and two other forms of pollution, passive smoking and noisy neighbours is also of interest. These two forms of pollution were chosen, as they should not correlate with industrial odour. Their association with high reporting of industrial odour would suggest that some people are more likely to report/complain about environmental pollution, whatever the source, than others. The psychological mechanisms for this are unclear and beyond the scope of the current discussion. However, it may well be that wider contextual factors, as discussed above, play a role. In this regard measures of, for instance, neighbourhood satisfaction, trust in industry/regulatory institutions or the success of previous complaints might add to our understanding of the factors that influence perceived severity of air pollution. This said, it is doubtful whether these factors would substantially affect the value of mean population perception as a measure for air pollution.

Of particular interest is the lack of any direct association between pollution reporting and smoking behaviour. Given the strong association between smoking and respiratory disease found in this study [9], the lack of an association with smoking is particularly surprising. In any event, the finding that smoking does not affect reporting of industrial odour pollution is reassuring. Geographical variations in smoking behaviour will have a major impact on risk of respiratory illness. As such they are potentially significant causes of bias in estimates of the impact of air pollution on health. The findings in this study are reassuring for the use of population perception as estimates of environmental exposure.

The study from which the analyses presented here was one of the larger cross-sectional surveys of the perception of air pollution to have been reported from a single small geographical area. However, the response rate was only a little over $50 \%$. Such low response rates raise the possibility of selection bias. For example, response rates were poorer in 
more deprived areas [10]. Nevertheless, because the dependant variable was whether or not an individual reported pollution more or less frequently than others in his/her local area such biases would not have a marked affect on the conclusions drawn.

\section{Conclusions}

In conclusion, a number of factors have been found to influence an individual's propensity to report higher levels of industrial odour pollution than others in their area. However, with the possible exception of variation in belief about whether air pollution is harmful, the data from this study indicate that such factors are unlikely to have a major impact on the use of mean or median population perception as an indictor of exposure. Such belief, that air pollution is harmful, is likely to be related to a number of contextual issues, such as local media reporting and the social amplification of risk and should be considered in any epidemiological study. This said, the findings support a need for additional research to enable more sophisticated analyses of public perceptions, which explore how aspects of social context influence estimations of pollution severity, the sources of evidence that people draw upon and the correspondence between perception and a range of pollution measures.

\section{List of abbreviations}

SPSS - Statistical Package for the Social Sciences

\section{Competing interests}

None declared.

\section{Authors' contributions}

PRH led the original study, undertook the analyses and led on the drafting of the manuscript.

KB provided a social and psychological interpretation of the data and contributed to the drafting of the manuscript.

MAD Contributed to the design of the original study, was responsible for the management of the survey and contributed to drafting of the manuscript.

\section{References}

I. Izzotti A, Parodi S, Quaglia A, Fare C, Vercelli M: The relationship between urban airborne pollution and short-term mortality: quantitative and qualitative aspects. Eur J Epidemiol 2000, 16:1027-1034.

2. Pope CA 3rd: What do epidemiologic findings tell us about health effects of environmental aerosols? J Aerosol Med 2000, 1 3:335-354.

3. Romieu I, Samet JM, Smith KR, Bruce N: Outdoor air pollution and acute respiratory infections among children in developing countries. J Occup Environ Med 2002, 44:640-649.

4. Leikauf GD: Hazardous air pollutants and asthma. Environ Health Perspect 2002, I I O(Suppl 4):505-526.

5. Delfino RJ: Epidemiologic evidence for asthma and exposure to air toxics: linkages between occupational, indoor, and community air pollution research. Environ Health Perspect 2002, I I 0(Suppl 4):573-589.
6. Ibald-Mulli A, Wichmann HE, Kreyling W, Peters A: Epidemiological evidence on health effects of ultrafine particles. J Aerosol Med 2002, I5:189-20I.

7. International Programme on Chemical Safety: Human Exposure Assessment Geneva: World Health Organization; 2000.

8. Oglesby L, Künzli N, Monn C, Schindler C, Ackermann-Liebrich U, Leuenberger P: Validity of annoyance scores for estimation of long term air pollution exposure in epidemiological studies: the Swiss Study on Air Pollution and Lung Diseases in Adults (SAPALDIA). Am J Epidemiol 2000, 152:75-83.

9. Weiland SK, Nundt KA, Ruckmann A, Keil U: Self-reported wheezing and allergic rhinitis in children and traffic density on street of residence. Ann Epidemiol 1994, 4:243-247.

10. Hunter PR, Davies MA, Hill K, Whittaker M, Sufi F: The prevalence of self-reported symptoms of respiratory disease and community belief about the severity of pollution from various sources. Int J Environ Health Res 2003, 13:227-238.

II. Forsberg B, Stjernberg N, Wal S: People can detect poor air quality well below guideline concentrations: a prevalence study of annoyance reactions and air pollution from traffic. Occup Environ Med 1997, 54:44-48.

12. Luginaah IN, Taylor SM, Elliott SJ, Eyles JD: Community reappraisal of the perceived health effects of a petroleum refinery. Soc Sci Med 2002, 55:47-61.

13. Office of Population Censuses and Surveys: Classification of Occupations London: Her Majesty's Stationery Office; 1980.

14. McCarron P, Harvey I, Brogan R, Peters TJ: Self reported health of people in an area contaminated by chromium waste: interview study. Brit Med J 2000, 320: I I- 15.

15. Breer $H$ : Sense of smell: recognition and transduction of olfactory signals. Biochem Soc Trans 2003, 3 I: I I3-I I6.

16. Sarkara U, Longhurstb PJ, Hobbs SE: Community modelling: a tool for correlating estimates of exposure with perception of odour from municipal solid waste (MSW) landfills. J Environ Manage 2003, 68: 133-140.

17. Rothman KJ, Greenland S: Accuracy considerations in study design. In: Modern Epidemiology 2nd edition. Edited by: Rothman KJ, Greenland S. Philadelphia, Lippincott, Williams and Wilkins; 1998:135-145.

18. Hunter PR, Syed Q: Recall bias in a community survey of selfreported gastroenteritis undertaken during an outbreak of cryptosporidiosis strongly associated with drinking water after much press interest. Epidemiol Infect 2002, 1 28:433-438.

19. Cockburn M, Hamilton A, Mack T: Recall bias in self-reported melanoma risk factors. Am J Epidemiol 2001, I 53:102 I-1026.

20. Kip KE, Cohen F, Cole SR, Wilhelmus KR, Patrick DL, Blair RC, Beck RW: Recall bias in a prospective study of acute time-varying exposures: examples from the herpetic eye disease study. J Clin Epidemiol 200I, 54:482-487.

21. Teschke K, Smith JC, Olshan AF: Evidence of recall bias in volunteered vs. prompted responses about occupational exposures. Am J Ind Med 2000, 38:385-388.

22. Barry $D$ : Differential recall bias and spurious associations in case/control studies. Stat Med 1996, 15:2603-2616.

23. Howel D, Moffatt S, Bush J, Dunn CE, Prince H: Public views on the links between air pollution and health in Northeast England. Environ Res 2003, 91 : 163-17I.

24. Pidgeon N, Henwood K, Maguire B: Public health communication and the social amplification of risks: present knowledge and future prospects. In: Risk Communication and Public Health Edited by: Bennet P, Calman K. Oxford, Oxford University Press; 1999:65-77.

25. Frewer LJ, Miles S, Marsh R: The media and genetically modified foods: evidence in support of social amplification of risk. Risk Anal 2002, 22:70I-7II.

26. Elliott SJ, Cole DC, Krueger P, Voorberg N, Wakefield S: The power of perception: health risk attributed to air pollution in an urban industrial neighbourhood. Risk Anal 1999, 19:621-634.

27. Howel D, Moffatt S, Prince H, Bush J, Dunn CE: Urban air quality in North-East England: exploring the influences on local views and perceptions. Risk Anal 2002, 22: 12 I-I 30.

28. Šlachtová $H$, Tomášek I, Jones $K$, Vašina $B$, Volf J: Risk reception study in the framework of PHARE/CESAR study - central European study on air pollution and respiratory health. Risk perception, the environment, and communication strategies 
in the CESAR project: results from the Czech Republic. J Hazard Materials 1998, 61:313-317.

29. Bickerstaff $K$, Walker $G$ : Public understandings of air pollution: the 'localisation' of environmental risk. Global Environ Change 200I, I I:I33-I45.

30. Bickerstaff K, Walker G: The place(s) of matter: matter out of place - public understandings of air pollution. Prog Human Geog 2003, 27:45-67.

31. Johnson BB: Gender and race in beliefs about outdoor air pollution. Risk Anal 2002, 22:725-738.

32. Bickerstaff $K$, Walker $G$ : Clearing the smog: public responses to air quality information. Local Environ 1999, 4:279-294.

33. Walker G, Simmons P, Irwin A, Wynne B: Public perception of risks associated with major accident hazards. Research Report Series 194/98 Sudbury, HSE Books; 1998.

34. Bush J, Moffatt S, Dunn C: Even the birds round here cough: stigma, air pollution and health in Teesside. Health Place 200I, 7:47-56.

35. Moffatt S, Bush J, Dunn C, Howel D, Prince H: Public awareness of air quality and respiratory health and the impact of health advice Newcastle, University of Newcastle; 1999.

36. Burningham K, Thrush D: 'Rainforests are a long way from here': the environmental concerns of disadvantaged groups Guildford, University of Surrey; 200I.

37. Moffatt S, Hoeldke B, Pless-Mulloli T: Local environmental concerns among communities in North-East England and South Hessen, Germany: the influence of proximity to industry. J Risk Res 2003, 6: I25-|144.

Publish with Bio Med Central and every scientist can read your work free of charge

"BioMed Central will be the most significant development for disseminating the results of biomedical research in our lifetime. "

Sir Paul Nurse, Cancer Research UK

Your research papers will be:

- available free of charge to the entire biomedical community

- peer reviewed and published immediately upon acceptance

- cited in PubMed and archived on PubMed Central

- yours - you keep the copyright

Submit your manuscript here:

http://www.biomedcentral.com/info/publishing_adv.asp
BioMedcentral 